\title{
Visual Filtering and Covert Orienting in Persons with Down Syndrome
}

\author{
Beth Randolph \\ Department of Educational and Counselling Psychology \\ McGill University \\ Montreal \\ - 1994
}

\author{
A Thesis \\ submitted to the Faculty of Graduate Studies and Research \\ of McGill University \\ in partial fulfilment of the requirements of \\ the degree of Master of Arts \\ in Educational Psychology
}




\begin{abstract}
A forced-choice reaction time (RT) task was used to examine the relations between covert orienting (shifts of visual attention independent sf eye movement) and filtering (the inhibition of processing of urrelevant stunuli) components of attention in persons with Down syndrome $(\underline{n}=17)$ and children of average intelligerice $(\underline{n}=17)$ matched for mental age (MA), $(M A=$ approximately 5 years). Conditions varied with regard to presence or absence of distractors, and the validity (valid, invalid, or neutral) of location cues. $\mathrm{RT} / \mathrm{p}$ (correct) scores of both groups were longer in distractor-present conditions and in conditions when the location cue provided incorrect information (invalid cue). In addition, RT/p(correct) scores of both groups were longer when it was necessary to simultaneously search for a target and filter out irrelevant information, than when each of these attention demanding tasks was utilized separately. However, there were no differences in performance between persons with Down syndrome and MA matched children of average intelligence. This evidence is used to challenge the notion of an overall deficit in selective attention abilities in persons with Down syndrome as compared to MA matched children of average intelligence. Findings are also discussed in erms of their support for a capacity sharing relationship between covert orienting and filtering.
\end{abstract}




\section{RESUME}

Une tâche sur le temps de réaction (TR) de choix-forcé a été utlisée pour examiner les relations entre une orientation dissimulée (changement de l'attention visuel independant du mouvement de l'oell) et le filtrage (l'inhibition du tratement des stimuli non pertinents) les composantes d'attention des personnes Trisomie $21(\underline{n}=17)$ et des enfants d'une intelligence moyenne ( $\underline{n}=17)$ correspondant a l'âge mental (AM) $(A M=$ approximativement 5 ans). Les conditions ont varié à l'égard de la presence ou de l'absence de distractions et la validité (valide, non valide, ou neutre) des indices de localisation. Les TRs pour les deux groupes étaient plus lents dans des conditions distraction-presents et dans des conditions ou l'indice de localisation pourvoyait de l'information incorrecte (indication non valide). De plus, les TRs des deux groupes en question étaient plus lents lorsqu'il était necessaire de chercher, simultanement, une cible et de filtrer l'information non pertinente, que lorsque chacune de ces tâches qui demande de l'attention, étaient utilisées separément. Parcontre, il n'y avait pas de différence dans la performance entre les personnes Trisomie 21 et les enfants correspondants à leurs AMs et d'une intelligence moyenne. Cette démonstratıon est utılısée pour contester la notioiı d'un manque général dans les habiletés d'attention séléctive des personnes Trisomie 21 en comparant ces derniers avec des enfants d'une intelligence moyenne et correspondants a leurs AMs. Ces decouvertes sont aussi discutées pour supporter un notion d'un relation en terme de capacite partagé entre orientation dissimulée et le filtrage visuel. 


\section{ACKNOWLEDGEMENTS}

There are four very special pecple in my life to whom I would like to dedicate this work. Mom and Dad, you have stuck by me through all the rough times, and for that I thank you. Your endless love, support and patience has provided me with the strength to reach this career milestone. Mark, thank you for sharing your room, your computer and most of all your sense of humour. Can you believe it, I'm actually done! Andrea, your encouragement and concern reached out over the many miles that separate us. Thank you for not forgetting about your little sister.

I would like to acknowledge the person who helped make this project possible, Prof. Jake Burack. It is through your exceptional guidance and continual support that I gained the strength to complete this endeavour. The perfect blend of humour and knowledge that you convey made even the most difficult times seem bearable. I would also like to express my sincere gratitude to Selma Abu-Merhy for always being there when I needed someone to talk to.

I wish to express my appreciation to the staff and clients of Les Promotions Sociales Taylor-Thibodeau, Summit School, Camp Reena, Temple Emmanuel Pre-school and Elizabeth Ballantyne School. This research would not have been possible without their participation and cooperation. Their willingness to give their time and help did not go unnoticed.

I owe much to my friends who have put up with me through all my 
complaints and bad moods. Your understanding and encouragement has taught me the true meaning of friendship. I would like to especially thank Elizabeth Benedetto and Roi yn Toban. Liz, your giving nature and friendly disposition made our year of data collection something I will not soon forget. I thank you for being not only my source of information, but for helping me mantain my sanity. Rob, you always know just the right thing to say to make me smile. Thank you for always being there and for having the faith in me that I sometimes did not have in myself.

Finally, I would like to say a special thank you to Pookie, for always being willing to help, and to Sockie, for keeping me company when no one else was around. 
Abstract

Resume iii

Acknowledgements

iv

Table of Contents vi

List of Tables viii

Figure Captions ix

CHAPTER 1 Introduction i

Visual Selective Attention 2

Developmental Issues in the Relations

Between Filtering and Covert

Orienting.

Issues in the Study of Filtering and

Covert Orienting in Persons with Down

Syndrome

Subjects

Experimental Task

Kaufman Brief Intelligence Test

Procedure 15

Measuring Performance 
Page

CHAPTER 3

Results

20

Gender Analysis ......................... 20

General Analysis ......................... 20

CHAPTER $4 \quad$ Discussion ...................................... 25

Functioning of Visual Filterng

Mechanisms ......................... 25

Functioning of Covert Orienting

Mechanisms ......................... 26

Relations Between Filtering and Covert

Orienting ........................... 26

Conclusion ................................ 28

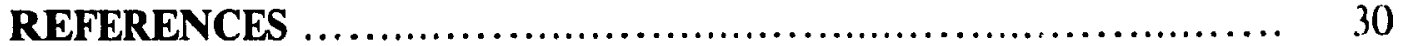




\section{LIST OF TABLES}

Page

Table 1. Mean Chronological Age (CA) and Mental Age (MA) of Subject

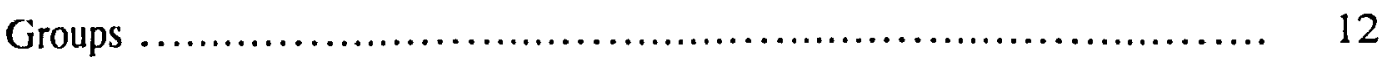

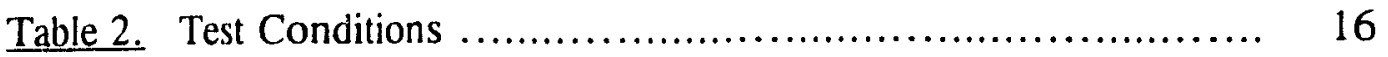




\section{FIGURE CAPTIONS}

\section{Page}

Figure 1. Dimensions of Target Stimuli, Location Cue and Distractors

Figure 2. Test Conditions

Figure 3. Mean Combined Score (RT/p[correct]), Plotted as a Function of

Diagnosis, Orienting and Filtering condition

Figure 4. Mean Correct RT, Plotted as a Function of Diagnosis, Orienting and Filtering condition

Figure 5. Mean Percentage Errors, Plotted as a Function of Diagnosis,

Orienting and Filtering condition 


\section{Visual Filtering and Covert Orienting \\ in Persons with Down Syndrome}

Impairments in the development of various components of attention in

persons with Down syndrome have been cited (Krakow \& Kopp, 1983; Landry \& Chapieski, 1989). For example, infants and children with Down syndrome have difficulty switching their visual attention from one stimuli to another and are consequently unable to attend to more than one aspect of their environment without confusion (Krakow \& Kopp, 1983; Landry \& Chapieski, 1989). Children with Down syndrome also exhibit difficulties maintaining attention to task-relevant stimuli when extraneous auditory stimuli are present in their environment (Miezejeski, 1974). Similarly, as compared with infants with mental retardation of unknown etiology (Krakow \& Kopp, 1983) and premature infants at risk for developmental delay (Landry \& Chapieski, 1989), infants and children with Down syndrome were more likely to focus on either irrelevant aspects of a presentation (Landry \& Chapieski, 1989) or on only one of the relevant aspects of it (Krakow \& Kopp, 1983). This is indicative of the ability of infants and children with Down syndrome to process only a small amount of the information available to them. This limited ability restricts their learning potential (Stratford, 1985).

The difficulties that infants and children with Down syndrome exhibit on tasks requiring them to ignore extraneous stimuli in order to process relevant stimuli (Miezejeski, 1974) and to efficiently switch from one aspect of 
a presentation to the other (Landry \& Chapieski, 1989; Krakow \& Kopp. 1983) are evidence of deficits in the areas of visual filtering and covert orienting. Visual filtering is the attentional component responsible for focusing on relevant stimuli and ignoring urrelevant stimuli (Enns, 1990). Covert orienting is the attentional component responsible for shıfts in visual attention independent of eye movement (Brodeur, 1990). The focus of this study is the specific assessment of the effects and relationshıps of filtering and covert orienting components of visual selective attention in persons with Down syndrome.

\section{Visual Selective Attention}

In an analysis of the development of visual selective attention, Enns (1990) conceptualizes visual selective attention as a hierarchy of mechanisms.

Selectivity, the ability to focus on task relevant information leading to efficient processing, is at the highest level of the hierarchy. Among the specific components of visual attention that are at the next level, Enns (1990) highlights filtering and orienting (or search) as essential components for selectivity.

Filtering is defined as the ability to inhibit the processing of task irrelevant information in order to efficiently process relevant information. The orienting component, in general, is responsible for the alignment of visual processing resources with target objects so that efficient processing of targets will occur. The orienting component is further subdivided into overt orienting 
and covert orienting. Overt orienting refers to the alignment of sensory resources that is dependent upon head and eye movements (Brodeur, 1990). For example, sensory resources, such as the retinal receptors present at the fovea, are aligned with the target through head and eye movements (Enns, 1990). Covert orienting refers to the alignment of cognitive resources, as it is independent of head and eye movement (Brodeur, 1990). For example, cognitive resources, such as the attentional facilitation of s.ecific regions of visual space, are aligner with a target by salient visual cues that are Independent of head or eye movement (Enns, 1990).

The present study will focus on covert, as opposed to overt orienting as the mechanisms needed for overt orienting may not require attention at all (Enns, 1990). Instead, functioning of the overt orienting component may reflect physiological factors that are independent of attention, such as oculomotor control (Kowler \& Martins, 1982), and/or peripheral visual acuity (Taylor, 1982). Whereas covert orienting functions exclusively through cognitive (internal) mechanisms that require attention, overt orienting relies on the development of sensory and motor mechanisms for eye movement control. Developmental Issues in the Relations Between Filtering and Covert Orienting Young children are typically less efficient than older children and adults in selecting relevant visual informaition under varying conditions (eg., Akhtar \& Enns, 1989; Enns \& Brodeur, 1989; Lane \& Pearson, 1983; Pearson \& Lane, 1990; Tipper, Bourque, Anderson, \& Brehaut, 1989). More 
specifically, age-related improvements are found on tasks of covert orıentıng (Akhtar \& Enns, 1989; Enns \& Brodeur, 1989) and visual filtering (Enns \& Akhtar, 1989; Enns \& Girgus, 1985; Tipper et al., 1989).

Improvements with age in both filtering and covert orienting have been explained in the context of two dichotomous theories: the capacity limited and strategy deficit views. These different views of the development of attentional skills represent divergent notions of the relationship between resources of attention. According to the capacity limited view, attention is a single cognitive resource of limited capacity with components that interact with one another in a capacity sharing fashion (Allport, 1989; Broadbent, 1971; Enns \& Brodeur, 1989; Kahneman, 1973). The simultaneous use of two or more of these components may have two possible effects on performance. One, the limited resources may be drained by the simultaneous use of two components, thereby resulting in poorer performance. Alternatively, the components may work together in a facilitative manner, thereby requiring fewer resources and resulting in improved performance (Akhtar \& Enns, 1989; Enns, 1990; Mesulam, 1985). Within the capacity limited view, attentional mechanisms increase in efficiency with maturation and experience (Pascuale-Leone, 1978). Therefore, age-related improvements in selectivity are attributed to further development and maturation of the attentional mechanisms (Enns \& Akhtar, 1989).

According to the strategy deficit view, attention is made up of multiple 
mechanisms that do not share processing resources (Enns \& Cameron, 1987). Attention is seen as a collection of independent skills and components that permit the processing of selected information (Enns \& Akhtar, 1989; Hirst \& Kalmar, 1987). For example, functioning of the component of overt orienting in tasks was found to be unrelated to certain components of visual attention such as filtering (Enns \& Cameron, 1987). The issue of capacity limits is not relevant to performance on tasks requiring attention. Instead, performance is determined by subjects' ability to skillfully allocate cognitive resources to the relevant task components (Enns \& Brodeur, 1989). Therefore, the poorer performance of younger children is attributable to their use of inadequate strategies in allocating cognitive resources to task components rather than to their underdeveloped attentional capacity (Chi, 1976; Geffon \& Sexton, 1978).

The additive factors method (Enns \& Cameron, 1987) has been considered a useful framework within which to assess the relative validity of the capacity limited and strategy deficit views (Enns, 1990). The logic of the additive factors method is based on the notion that if two task components rely on a single attentional mechanism for their efficient execution, as in the capacity limited view, then the utilization of both components simultaneously should have either a facilitating or hindering effect on performance (Enns, 1990). Alternatively, if the cognitive resources required for two task components are independent, as in the strategy deficit view, then performance should not be effected when more than one task component is used (Akhtar \& 
Enns, 1989).

Using the method of additive factors as a context within which to analyze their findings, Enns and colleagues (Akhtar \& Enns, 1989; Enns \& Akhtar, 1989; Enns \& Brodeur, 1989; Enns \& Cameron, 1987) examined the relations between covert orienting and filtering components of attention. The finding that the simultaneous use of covert orienting and filtering directly effects task performance provides support in favour of the capacity limited view. When a cue provided accurate information regarding the location of a subsequent target (i.e. attentional facilitation), subjects were able to focus on relevant stimuli and efficiently inhibit the processing of distracting stimuli. However, when a cue provided erroneous information regarding the location of a subsequent target, the ability to inhibit the processing of distracting stimuli was significantly diminished (Enns, 1990). The markedly different effects of the two covert orienting conditions (valid location cue and invalid location cue) on filtering efficiency implies a capacity sharing relationship between covert orienting and filtering components of visual attention.

Issues in the Study of Filtering and Covert Orienting in Persons with Down Syndrome

Fiitering and covert orienting have not been systematically studied among persons with Down syndrome, but there is minimal evidence from related studies that these processes are deficient in this population. Persons with Down syndrome are less able to effectively attend to more than one 
aspect of their environment as they tend to shift their attention inapproprately from sne stimulus to the next, and therefore, they do not process the relevant informatio'ı (Krakow \& Kopp, 1983; Landry \& Chapieski, 1989). They also have difficultıes focusing on only one relevant aspect of a multi-faceted presentation and ignoring the Irrelevant ones (Krakow \& Kopp, 1983). Under such circumstances, their accuracy in task performance declines as they are distracted by the irrelevant stimuli in their environment (Lunzer \& Stratford, 1984; Miezejeski, 1974; Zekulen, Gibson, Mosley, \& Brown, 1974).

The purpose of the present study is to assess the effectiveness of covert orienting and visual filtering in persons with Down syndrome and MA matched children of average intelligence. In this manner, the "Normalcy Question" (Wagner, Ganiban, \& Cicchetti, 1990), that asks whether the processes that underlie the development of children with Down syndrome differ from those of normally developing children with the same MA, will be applied to the study of visual filtering and covert orienting. By assessing the differences and similarities between persons with Down syndrome and MA matched children of average intelligence with regard to the functioning of the components of covert orienting and visual filtering, it will be possible to determine whether persons with Down syndrome possess a deficit in these components, or whether their performance is appropriate for their general level of cognitive functioning.

A modified version of a forced choice reaction time (RT) task (Akhtar 
\& Enns, 1989) was used to assess the presence or absence of deficits in filtering and covert orienting in persons with Down syndrome and an MA matched group of persons with average intelligence. Subjects were asked to respond to the presentation of one of two target stimul, a circle $(O)$ or a plus $(+)$ on a computer screen, by pressing an appropriate response button. On each trial, a cue, a flash of light, was initially presented. The cue was presented either at the midpoint of the screen, directly to the right of the midpoint or directly to the left of the midpoint, and provided three types of information. One, as a valid cue it provided correct information about the location of the target that subsequently appeared in the spot either to the left or right of the midpoint of the screen. Two, as an invalid cue it provided incorrect information about the location of the subsequent taiget. Three, as a neutral cue it provided no information aùout the location of the subsequent target as it appeared at the midpoint of the screen where the target was never found.

In order to ensure that the task was measuring covert orienting as opposed to overt orienting, the interval between the cue and the target was 150 ms, less time than necessary to initiate an eye movement (Akhtar \& Enns, 1989). This ensured that the shift of attention required to respond to the target stimulus was independent of head and eye movements.

After the presentation of the cue, the target stimulus $(\mathrm{O}$ or +$)$ appeared either $(6 \mathrm{~cm})$ directly to the left or $(6 \mathrm{~cm})$ directly to the right of the midpoint 
of the screen (6.87 degree visual angle from the midpoint of the screen). On half the trials, the target appeared alone, and on the other half the target was flanked on either side by distracting stimuli. Filtering was assessed by comparing performance on conditions with and without distractors.

The dependent variable was the mean of the median correct reaction time divided by the proportion of correct responses [RT/p(Correct)] (Akhtar \& Enns, 1989). This measure estimates the overall efficiency of performance on a forced choice RT task as well as accounts for the errors committed by the subjects.

The task used in the present study differed from the original (Akhtar \& Enns, 1989) in three ways. One, the distractors that flank the target were always different from the target as the issue of compatible versus incompatible distractors was not considered. Two, feedback was not provided regarding the accuracy of the subject's previous response with the intention of keeping the task as simple as possible. Three, the target display remained on the screen until the subject responded rather than being removed after $50 \mathrm{~ms}$. This minimized any group differences in memory.

Several general hypotheses were made. One, shorter RT/p(correct) scores were expected in conditions without distractors and with the valid location cue. Two, longer RT/p(correct) scores were expected in conditions with distractors and with the invalid location cue. Three, performance was expected to be either shorter or longer when the components of filtering and 
covert orienting were used simultaneously. For example, longer RT/p(correct) scores were expected when invalid location cues were followed by targets with distractors, shorter $\mathrm{RT} / \mathrm{p}$ (correct) scores were expected when valıd location cues were followed by targets with distractors, and even shorter RT/p(correct) scores were expected when valid location cues were followed by targets without distractors. Four, consistent with the view of attention deficits in persons with Down syndrome, it was predicted that the $\mathrm{RT} / \mathrm{p}$ (correct) scores of this group would be longer than those of MA matched children of average intelligence in the presence of distractors and invalid cues.

\section{Method}

\section{Subjects}

Subjects included 17 persons with Down syndrome (5 female, 12 male) and 17 children of average intelligence ( 11 female, 6 male). Persons with Down syndrome were recruited from a residence for persons with intellectual handicaps and a private school for children with developmental delays. The children of average intelligence were recruited from private and pablic schools.

Background information with regard to the etiology of mental retardation, visual and gross motor functioning, and chronological age (CA) was collected from school and personal files. Persons with severe gross motor or visual difficulties or persons who were tested but judged unable to perform the task as required were excluded from the study. The Matrices subtest of 
the Kaufman Brief Intelligence Test (Kaufman \& Kaufman, 1990) was used to obtain an approxımate measure of level of cognitive functionıng (i.e. MA) for all subjects. The average CAs and MAs of the two groups are presented in Table 1 .

Insert Table 1 about here

\section{Experimental Task}

All stimuli were presented on an IBM PS2 386/20 portable computer conr:-cled to a SVGA 14 inch IBM color monitor and a Genus Hi Trak mouse with two response buttons. There was a picture of a circle $(0)$ on the left response button and a picture of a plus $(+)$ on the right response button.

Subjects sat approximately $50 \mathrm{~cm}$ from the screen. Each trial began with a tone that signalled the presentation of stimuli. At the offset of the tone, a locational cue, a spot of light $1 \mathrm{~mm}$ in diameter, appeared for $50 \mathrm{~ms}$ in one of three places on the screen: (a) the midpoint of the screen; (b) $6 \mathrm{~cm}$ directly to the right of the midpoint (6.87 degree visual angle from the midpoint of the screen); or (c) $6 \mathrm{~cm}$ directly to the left of the midpoint (6.87 degree visual angle). A target stimulus appeared on the screen $150 \mathrm{~ms}$ after the locational cue disappeared. Target stimuli consisted of a circle $(0)$ and a plus sign $(+)$, On some trials distracting stimuli appeared simultaneously with the target stimuli, flanking it on either side. The distractors included 4 graphic symbols 
Table 1

Mean Chronological Age (CA) and Mental Age (MA) of Subject Groups

\begin{tabular}{|c|c|c|c|c|}
\hline \multirow[t]{2}{*}{ Group } & \multicolumn{2}{|l|}{ CA } & \multicolumn{2}{|c|}{$\mathrm{MA}$} \\
\hline & $\underline{\mathbf{M}}$ & & $\underline{\mathbf{M}}$ & $\underline{\mathrm{SD}}$ \\
\hline $\begin{array}{l}\text { Down } \\
\text { Syndrome }\end{array}$ & 20.02 & 6.80 & 5.27 & 0.93 \\
\hline $\begin{array}{l}\text { Average } \\
\text { Intelligence }\end{array}$ & 5.49 & 0.93 & 5.4 .3 & 0.81 \\
\hline
\end{tabular}




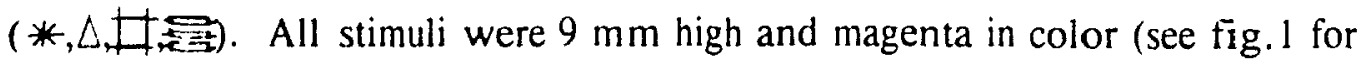
dimensions of location cue and target stımulı).

Insert Figure 1 about here

In each trial, one of the target stumuli was presented etther $6 \mathrm{~cm}$ directly to the left or $6 \mathrm{~cm}$ directly to the right of the midpoint of the screen (or at a 6.87 degree visual angle from the midpoint of the screen). Conditions varied with regard to the presence or absence of distractors. In some trials, the target stınuli was fianked on either side by distractors, in others there were no distractors present. The distractors were presented $1 \mathrm{~cm}$ to the right and left of the target (or at a 1.15 degree visual angle from the target).

Conditions also varied with regard to the position of the location cue (right, middle or left). In the valid cue condition, the cue appeared in the same position as the subsequent target (e.g. locational cue left, target left). In the invalid cue condition, the cue appeared in the position opposite to that of the subsequent target (e.g. locational cue left, target right). In the neutral cue condition, the cue appeared in the middle of the screen. The 6 Distractor $\mathrm{X}$ Locational Cue combinations are presented in Table 2. A graphic depiction of the 6 Distractor X Locational Cue combinations are presented in Figure 2. 


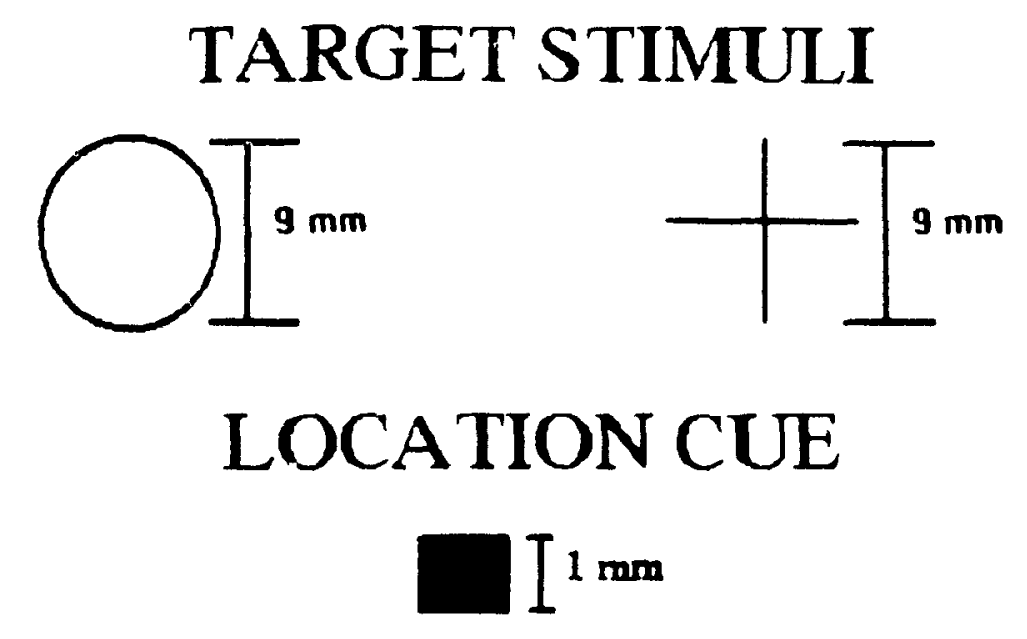

\section{DISTRACTORS}

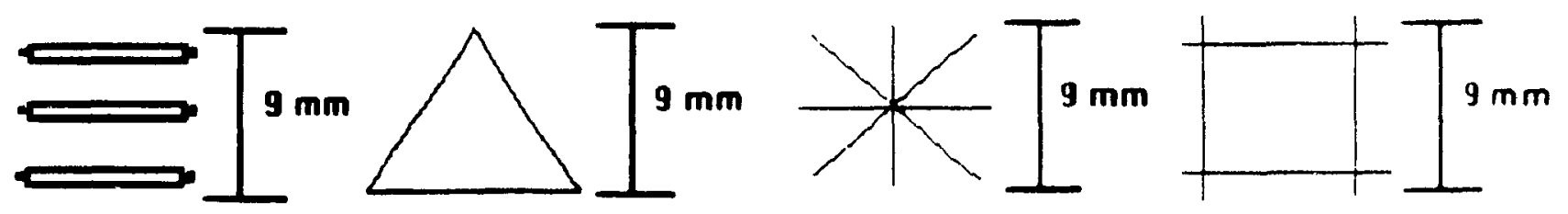

Eigune 1. Dimensions of target stmul, location cue and distractors 
Insert Table 2 and Figure 2 about here

There were 32 trials of each condition for a total of 192 trials. These trials were administered over two testing sessions with each session consisting of 2 sets of 48 trials separated by a 5 minute break. Eight trials (4 with a circle target stimulus and 4 with a plus target stimulus) of each of the 6 conditions were presented randomly in each of the sets of 48 trials.

Prior to both testıng sessions the subjects completed 2 sets of 10 practice trials. The first set consisted of trials with no distractors. The second set consisted of trials with distractors.

\section{Kaufman Brief Intelligence Test}

The Matrices subtest of the Kaufman Brief Intelligence Test (K-BIT) is considered to be a good measure of general cognitive functioning with splithalf and test-retest reliabilities of .85 and a construct validity of .56 with the Full Scale Intelligence Quotient (IQ) of the Wechsler Intelligence Scale for Children - Revised (WISC-R) (Kaufman \& Kaufman, 1990).

\section{Procedure}

The participants were individually tested on three occasions. During the first session, the subjects were administered the Matrices subtest of the Kaufman Brief Intelligence Test (K-BIT).

The experimental task was presented during the second and third 
Table 2

Test Conditions

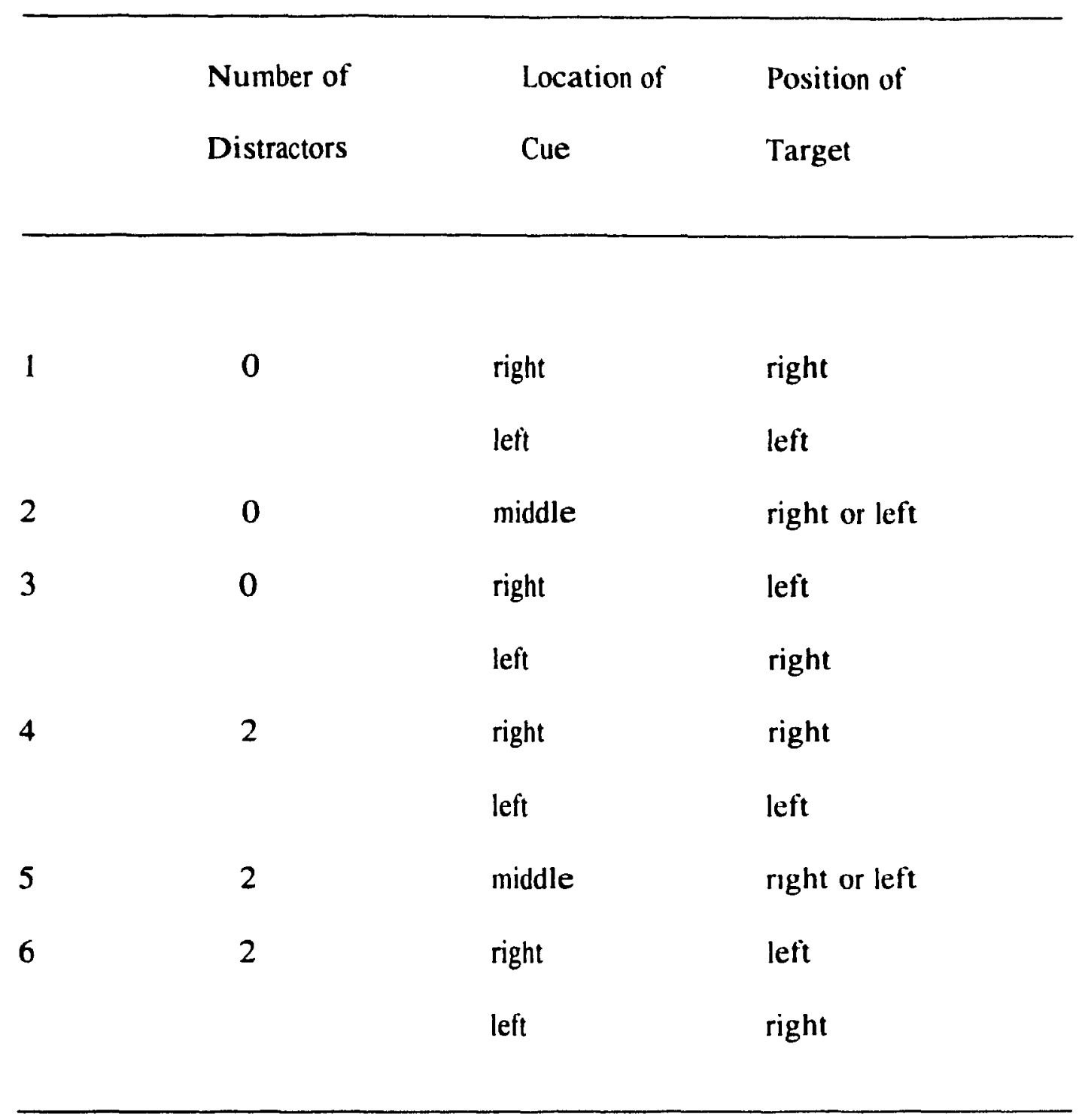


Selective Attention in Down Syndrome

17

\section{FILTERING}

No Distractors
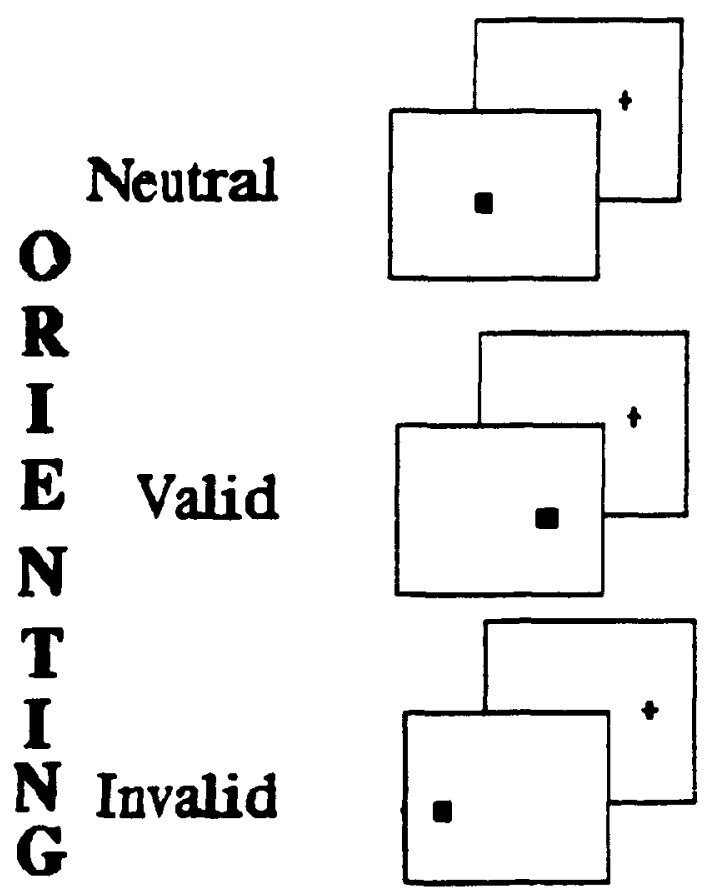

Two Distractors
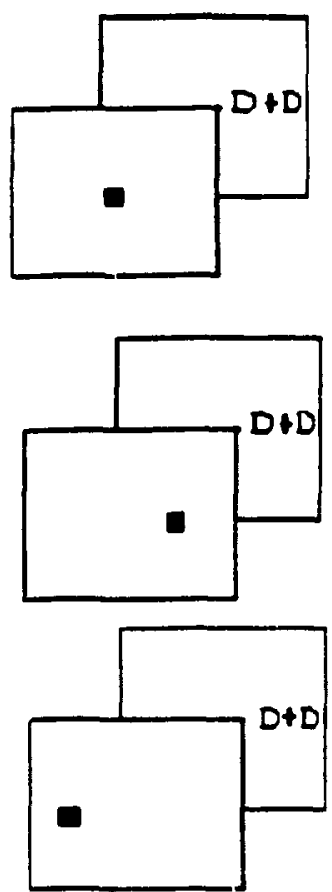

Eigure 2. Test conditions. 


\section{Selective Attention in Down Syndrome}

sessions. Subjects were seated at a table with their eyes approximately $50 \mathrm{~cm}$ from the computer screen and with the index finger of each hand resting on a response button. They were told by the experimenter:

Today we are going to play a game on the computer. Either a plus or a circle will appear on the screen in front of you. I want you to press the circle button (experimenter pointed to the circle response button) as fast as you can when you see a circle on the screen, and press the plus button (experimenter pointed to the plus response button) as fast as you can when you see a plus on the screen. The circles and pluses will appear on either this side (experimenter pointed to the left side of the screen) or this side (experimenter pointed to the right side of the screen).

Sometimes there will be other things on the screen besides the pluses and the circles. I want you to ignore them and just pay close attention to the pluses and the circles. OK? First we'll do some practice trials together and then you'll play the game by yourself. Remember, when you see a plus I want you to press the plus button as fast as you can and when you see a circle I want you to press the circle button as fast as you can. Are you ready?

The subjects were initially administered 2 sets of 10 practice trials.

Each trial was preceded by a one second tone that sounded to alert the subject 
to the presentation of stımuli. At the offset of the tone, a location cue appeared for $50 \mathrm{~ms}$. Following this, the screen was blank $150 \mathrm{~ms}$, and then the target stimulus and distractors, when relevant, appeared on the screen and remained there until the subject responded by pushing on one of the response buttons. After each trial, there was approximately a one second wait before the tone sounded again to begin the next trial. During the practice trials, subjects were given veroal feedback regarding the accuracy of their performance. Task instructions were repeated when deemed necessary by the experimenter.

Subjects were asked to begin the experimental task if they were correct on more than half of the practice trials, indicating that they understood the task and were not simply guessing. Those who were unable to perform at greater than chance accuracy were excluded from the study. The experimental trials were the same as the practice trials except that there was no feedback provided. After the practice trials were completed the subjects were asked:

Do you understand what you are supposed to do? OK, lets begin the game for real. Do the best you can.

\section{Measuring Performance}

It is common practice in studies examining reaction time scores to use median reaction times, especially when the subjects include children or other persons who typically display considerable variability in their RTs. Accordingly, the analyses were based on median correct reaction times of each 
subject for each of the 6 experimental conditions across the two testung sessions. The dependent measure used in the study was the mean of the median correct RT divided by the proportion of correct responses [RT/p(Correct)] (Akhtar \& Enns, 1989). The primary statıstical analyses were conducted with this measure as it estimates the uverall efficiency of performance and accounts for the errors committed by the subjects.

Results

The mean $\mathrm{RT} / \mathrm{p}$ (correct) scores for each group are plotted in Figure 3. The correct mean RTs and mean percentage errors are plotted in Figures 4 and 5.

Insert Figures 3,4 and 5 about here

\section{Gender Analyses}

A $2 \times 2 \times 3$ (Gender $\times$ Filtering $\times$ Orienting) repeated measures ANOVA was performed on the RT/p(correct) scores of both groups separately. Neither a main effect of gender nor an interaction between gender and filtering or covert orienting were found in these preliminary analyses. Accordingly, gender was not considered in the remainder of the analyses.

General Analyses

A $2 \times 2 \times 3$ (Group $\times$ Filtering $\times$ Orienting) repeated measures ANOVA revealed main effects of filtering $E(1,32)=44.31, \mathfrak{R}<.001$ and 
Selective Attention in Down Syndrome

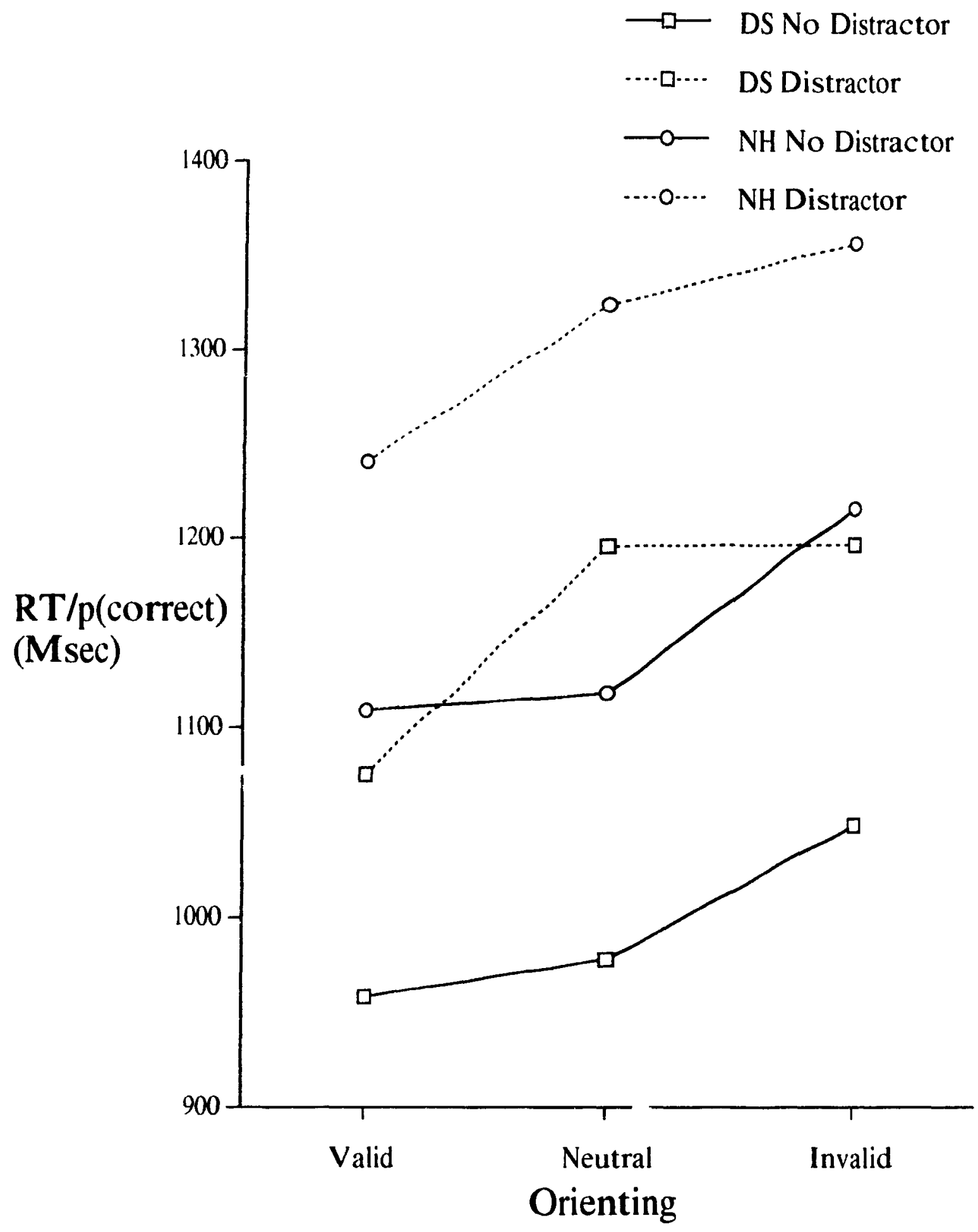

Figure 3. Mean combined score [RT/p(correct)], plotted as a function of diagnosis, orienting and filtering condition.

Note: $\mathrm{DS}=$ Down syndrome

$\mathrm{NH}=$ Nonhandicapped 
Selective Attention in Down Syndrome

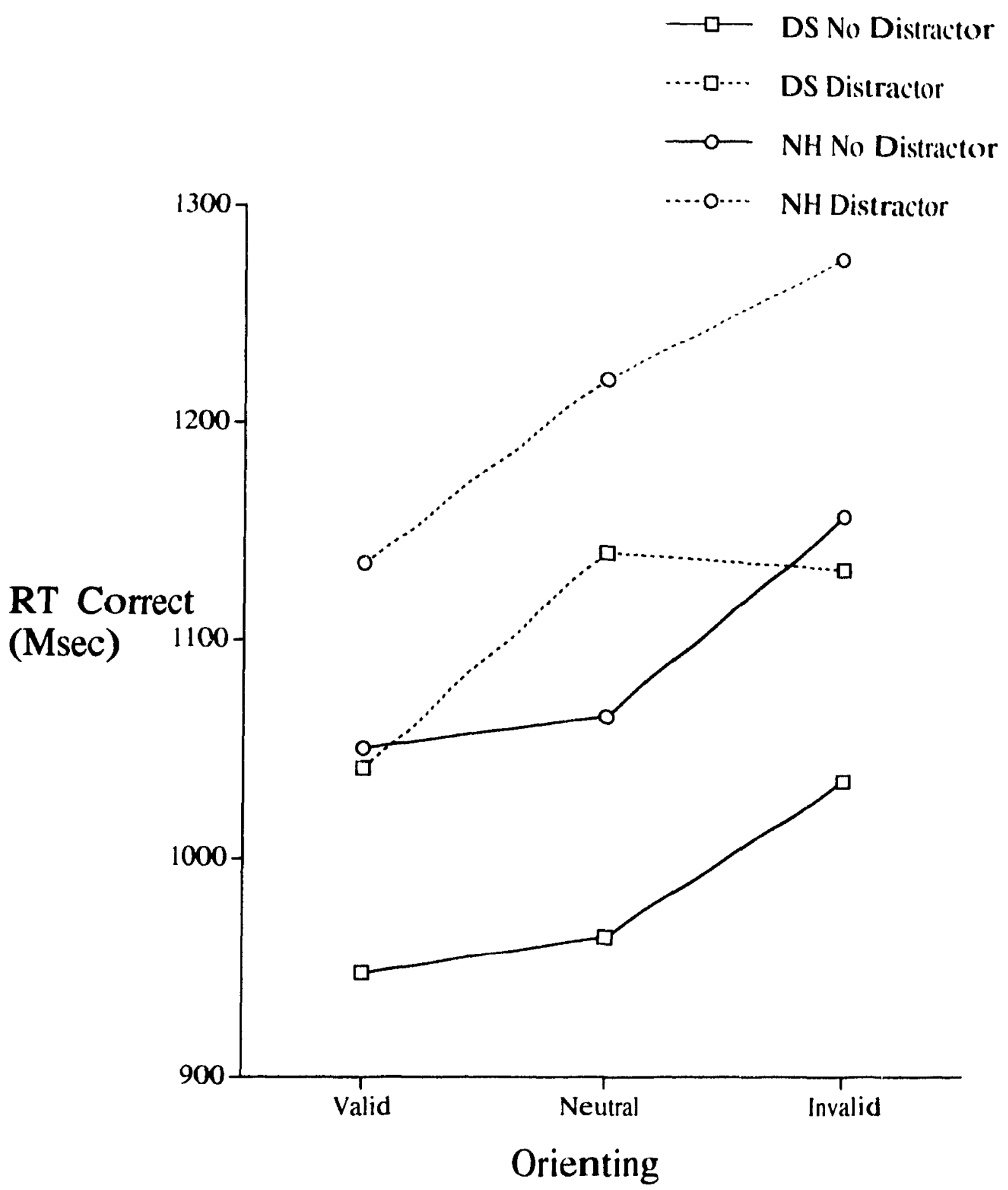

Figure 4. Mean correct RT, plotted as a function of diagnosis, orienting and filtering condition.

Note: $\mathrm{DS}=$ Down syndrome

$\mathrm{NH}=$ Nonhandicapped 


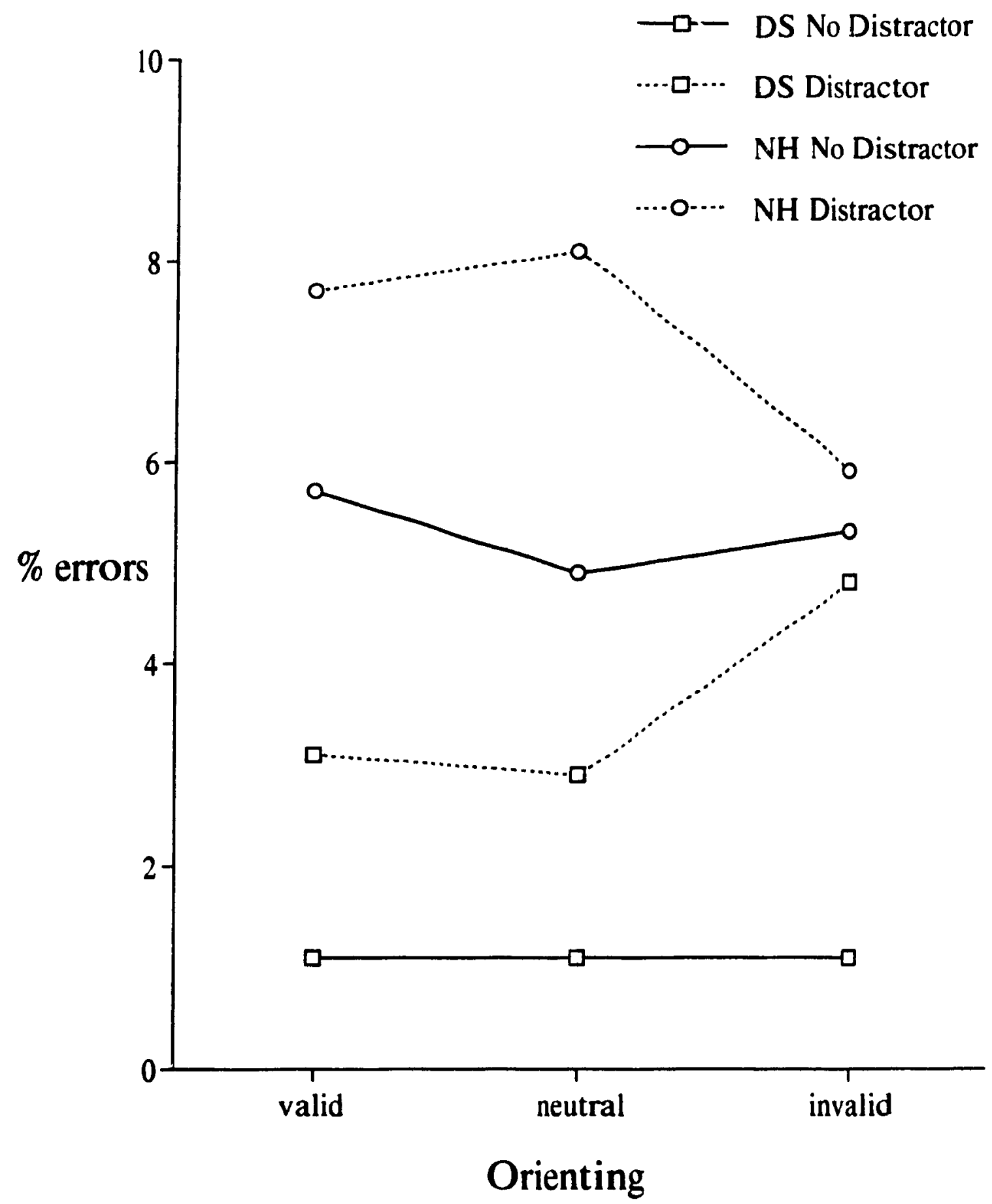

Figure 5. Mean percentage errors, plotted as a function of diagnosis, orienting and filtering condition.

Note: $\mathrm{DS}=$ Down syndrome

$\mathrm{NH}=$ Nonhandicapped 
orienting $\mathrm{E}(2,64)=12.45, \mathrm{p}<.001$, and a Filtering $\times$ Orienting interaction $\underline{F}(2,64)=3.59, \mathrm{p}<.05$. Neither a main effect of group nor an interaction hetween group and filtering or covert orienting were found.

The filtering main effect indicated longer $R T / p$ (correct) scores with distractors present. Newman Keuls post hoc comparisons (Glass \& Hopkins, 1984) were used to determine the source of the orienting main effect. These comparisons revealed that the subjects' RT/p(correct) scores were generally longer in conditions with invalid cueing as compared to those with valid cueing, $\mathbf{g}(32,3)=5.20, \mathfrak{p}<.05 . R T / p($ correct) scores in the neutr:ll cundition did not differ from those in either the invalid or valıd cueing conditions.

Simple effects tests and Fisher's LSD iests (Akhtar \& Enns, 1989; Keppel, 1973; Keppel \& Zedek, 1989) were used to determine the source of the Filtering x Orienting interaction. Simple effects tests reflected reliable interference effects of distractors with invalid $\underline{F}(1,198)=4.30, \mathfrak{R}<.05$ and neutral $\underline{F}(1,198)=9.25, \mathfrak{p}<.01$ cueing conditions, but not with valid cueing conditions. Fisher's LSD tests revealed significantly poorer performance for both groups on invalid and neutral conditions with distractors as compared to invalid and neutral no conditions without distractors (mean differences $=144$ and 211 respectively, both $\mathrm{p}$ values $<.05)$. No significant mean difference was found between valid distractor and valid no distractor conditions. 


\section{Discussion}

There were four primary findings of this study. One, both persons with Down syndrome and MA matched children of average intelligence displayed longer $\mathrm{RT} / \mathrm{p}$ (correct) scores when distractors were present in the visual field. Two, the performance of both groups was facilitated when a cue provided correct information about the location of the subsequent target, but inhibited when a cue provided incorrect information about the location of the subsequent target. Three, for both groups, there was no filtering interference effect in conditions of valit precue, while in conditions of invalid and neutral cueing, there was filtering interference. Four, contrary to exnectations, persons with Down syndrome showed a pattern of performance similar to that of MA matched children of average intelligence.

\section{Functioning of Visual Filtering Mechanisms}

The performance of subjects across groups was negatively affected by the presence of irrelevant information in the visual field. Longer $\mathrm{RT} / \mathrm{p}$ (correct) scores in conditions with distractors suggest a decreased ability to process and respond to relevant stimuli when extraneous stimuli are present in their visual field. The finding that persons with Down syndrome were no more adversely affected than MA matched children of average intelligence by the presence of distractors is discrepant with earlier findings of concentration difficulties and increased distractibility in persons with Down syndrome (Lunzer \& Stratford, 1984; Miezejeski, 1974; Zekulen et al., 1974). 
According to the present findings, the filtering mechanısms of persons with Down syndrome merely develop at a slower rate than those of children of average intelligence, but are comparable when matched for MA.

\section{Functioning of Covert Orienting Mechanisms}

Subjects in both groups displayed longer $\mathrm{RT} / \mathrm{p}$ (correct) scores in conditions with targets preceded by invalid cues as compared to those with targets preceded by valid cues. The average RT/p(correct) scores of both groups were approximately $100 \mathrm{~ms}$ shorter when the target was preceded by a valid cue as compared to an invalid cue, thus indicating the effectiveness of the valid cue and the interfering effects of the invalid cue.

The present findings indicate that valid visual cues draw attention to stimuli in the environment in both persons with Down syndrome and children of average intelligence. This is preliminary evidence that the mechanısms of covert orienting are intact and functional in persons with Down syndrome, as compared to MA matched children of average intelligence.

\section{Relations Between Visual Filtering and Covert Orienting}

The present findings support the capacity limited view and the notion that covert orienting, and filtering components require access to a single cognitive resource of limited capacity. When filtering and covert orienting components are required simultaneously, the limited resources may be drained by the simultaneous use of the two components, thereby resulting in poorer performance. Alternatively, the components may work together in a 
faciltative manner, thereby requiring fewer resources and resulting in improved performance (Akhtar \& Enns, 1989; Enns, 1990; Mesulam, 1985).

For both groups, the orienting of attention by the valid cue produced attentional shifts that eliminated filtering interference. The correct information provided by the valid cue required less resources to be allocatcu to the task, thus leading to more efficient filtering and faster responding. Conversely, the orienting of attention by the invalid and neutral cues produced attentional shifts that did not eliminate filtering interference. The incorrect and non-informative information provided by the cues required a greater number of resources to be allocated to the task, leading to a draining of resources and thus delayed responding in distractor conditions.

Further support for the capacity limited view emerges from data on performance with the neutral cue. In conditions without distractors, the neutral cue was not related to changes in performance. However, when distractors were included in the conditions with non-informative cues, performance was delayed as both components were simultaneously depleting the available resources. If covert orienting and filtenng were independent somponents of attention and did not share cognitive resources, then performance would be unchanged by the presence or absence of distractors in conditions of neutral cueing. However, the ability of subjects to respond to the target in conditions with a non-informative cue differed depending on the resources required in relation to the presence or absence of distractors. 
Selective Attention in Down Syndrome

Regardless of validity of the location cue, persons with Down syndrome were able to filter distracting stimul from their visual field as competently as MA matched children of average intelligence. Although delayed chronologically, the results suggest that the mechanıms required for efficient resource allocation are intact in persons with Down syndrome when compared to nonhandicapped children with the same MAs.

\section{Conclusions}

The present findings provide a response to the "Normalcy Question" (Wagner et al., 1990) with regard to the attentional functıonıng of persons with Down syndrome as compared to nonhandicapped children matched for MA. A deficit in the functioning of the mechanısms of visual filtering and covert orienting specific to persons with Down syndrome was not found. The overall pattern of covert orienting and filtering was sımilar for persons with Down syndrome and MA matched children of average intelligence. Both groups displayed longer $\mathrm{RT} / \mathrm{p}$ (correct) scores in the presence of distractors in their visual field, in conditions with an invalid locational cue, and in conditions where distractors were present with either an invalid or neutral locatıonal cue. The performance of both groups was facilitated in conditions without distractors and in conditions with a valid locational cue with or without distractors. These results indicate that the filtering and covert orienting mechanisms of persons with Down syndrome with an MA of 5-years-old are intact, and operate in the same manner and with the same degree of 
effectiveness as MA matched children of average intelligence.

The evidence of a capacity sharing relation between filtering and covert orienting supports the notion of shared cognitive resources between the two components of attentional selectivity. For both groups, the mechanisms of visual filtering and covert orienting rely on a common internal mechanism of selectivity for the allocatıon of cognitive resources to task components. 


\section{References}

Akhtar, N., \& Enns, J. T. (1989). Relations between covert orientıng and filtering in the development of visual attention. Journal of Experimental Child Psychology, 48, 315-334.

Allport, A. (1989). Visual Attention. In M. Posner (Ed.), Foundations of cognitive science. MIT: Cambridge, M.A.

Broadbent, D. E. (1991). Early selection, late selection, and the partitioning of structure. In R.G. Lockhead \& J.R. Pomerantz (Eds.), The perception of structure. Washıngton D.C.: American Psychological Association.

Broadbent, D. E. (1971). Decision and stress. London, Academic Press.

Brodeur, D. A. (1990). Covert orientıng in young children. In J. T. Enns (Ed.), The development of attention: Research and theory. New York: North Holland.

Chi, M. T. H. (1976). Short-term memory lımitations in children: Capacity or processing deficits? Memory and Cognition, 4, 559-572.

Day, M. C. (1978). Visual search by children: The effect of background variation and the use of visual cues. Journal of Experimental Child Psychology, 25, 1-16.

Enns, J. T. (1993). What can be learned about attention from studying it's development? Canadian Psychology, 34, 271-281.

Enns, J. T. (1990). Relations between components of visual attention. In J.T. 
Enns (Ed.), The development of attention: Research and theory. New York: North Holland.

Enns, J. T., \& Akhtar, N. (1989). A Developmental study in filtering in visual attention. Child Development, 60, 1188-1199.

Enns, J. T., \& Brodeur, D. A. (1989). A developmental i:udy of covert orienting to peripheral visual cues. Journal of Experimental Child Psychology, 48, 171-189.

Enns, J. T., \& Cameron, S. (1987). Selestive attention in young children: The relations between visual search, filtering, and priming. Journal of Experimental Child Psychology, 44, 38-63.

Enns, J. T., \& Girgus, J. S. (1985) Developmental changes in selective and integrative visual attention. Journal of Experimental Child Psychology, 40, 319-337.

Geffon, G., \& Sexton, M. A. (1978). The development of auditory strategies of attention. Developmental Psychology, 14, 11-17.

Glass, G. V., \& Hopkins, K. D. (1984). Statistical methods in education and psychology: 2nd Ed. Boston: Allyn and Bacon.

Hirst, W., \& Kalmar, D. (1987). Characterizing attentional resources. Journal of Experimental Psychology: General, 116, 68-81.

Kahneman, D. (1973). Attention and effort. Englewood Cliffs, NJ: PrenticeHall.

Keppel, G. (1973). Design and analysis: A researcher's handbook. 
Englewood Cliffs, NJ: Prentice-Hall.

Keppel, G., \& Zedek, S. (1989). Data analysis for research designs. New York: W.H. Freeman.

Krakow, J. B., \& Kopp, C. (1983) The effects of developmental delay on sustained attention in young children. Child Development, 54, 11431155.

Kowler, E., \& Martins, A. J. (1982). Eye movements of preschool children. Science, $\underline{21}$, 997-999.

Landry, S. H. \& Chapieski, M. L. (1989). Joint attention and infant toy exploration: Effects of Down syndrome and prematurity. Child Development, 60, 103-118.

Lane, D. M., \& Pearson, D. A. (1983). Attending to spacial locations: A developmental study. Child Development, 54, 98-104.

Lunzer, E. A., \& Stratford, B. (1984) Deficits in attention in young children with specific reference to Down's syndrome children and other mentally handicapped children. Early Child Development and Care, 17, 131-154.

Mesulam, M. M. (1985). Attention, confusional states, and neglect. In M. M. Mesulam (Ed.), Principles of behavioral neurology. Philadelphia: F.A. Davis.

Miezejeski, C. M. (1974). Effect of white noise on the reaction time of mentally retarded subjects. American Journal of Mental Deficiency, 
79, 39-43.

Miller, L. K. (1973). Developmental differences in the field of view during covert and overt search. Child Development, 44, 247-252.

Pascuale-Leone, J. (1978). Compounds, confounds, and models in developmental information processing: A reply to Trabasso and Foellinger. Journal of Experimental Child Psychology, 26, 18-40.

Pearson, D. A. \& Lane, D. M. (1990). Visual attention movements: A developmental study. Child Development, 61, 1779-1795.

Posner, M. I. (1980). Orienting of attention. Quarterly Journal of Psychology, 32, 3-25.

Stratford, B. (1980). Preferences in attention to visual cues in Down's Syndrome and normal children. Journal of Mental Deficiency Research, 24, 57-63.

Stratford, B. (1985). Learning and knowing: the education of Down's Syndrome children. In D. Lane, \& B. Stratford (Eds.), Current approaches to Down's syndrome. London: Holt, Rinehart and Winston.

Taylor, H. G. (1982). Age differences in peripheral letter perception. Journal of Experimental Psychology: Human Perception and Performance, 3, $106-112$

Tipper, S. P., Bourque, T. A., Anderson, S. H., \& Brehaut, J. C. (1989). Mechanisms of attention: A developmental study of experimental 
psychology. Journal of Experimental Child Psychology, 48, 353-378.

Wagner, S., Ganiban, J. M., \& Cicchetti, D. (1990). Attention, memory and perception in infants with Down syndrome: A review and commentary. In D. Cicchetti, \& M. Beeghly (Eds.), Children with Down syndrome: A developmental perspective. New York: Cambridge University Press.

Zekulen, X. Y., Gibson, D., Mosley, J. L., \& Brown, R. I. (1974). Auditory-motor channelling in Down's Syndrome subjects. American Journal of Mental Deficiency, 78, 571-580. 